\title{
BOTTOM-UP AND TOP-DOWN LISTENING PROCESSES WITHIN COGNITIVE CONSTRUCTIVIST LEARNING THEORY
}

\author{
Titis Sulistyowati \\ Universitas Muria Kudus, Indonesia
}

\begin{abstract}
The attention in Listening processes has switched from the text to the listener, from the process of identification to the process of understanding, and from the decontextualized memorization of definitions to developing language competence of students. This conception is then supported by the theory of congnitive constructivism which sees learning as the process of constructing new knowledge. This paper aims toexplore activities which can be applied to develop listening language skills in a context of authentic learning within constructivist learning approach. The learning activity will be based on the features of constructivism which views learning as an active process and knowledge is not absorbed passively but it is invented by the learners. By integrating the top-down and bottom-up listening processes and cognitive constructifist learning activities, this process will facilitate students in elaboratingtheir previous knowledge and constructing new knowledge.
\end{abstract}

Key words: bottom-up and top-down listening process, cognitive constructivist learning theory

\section{INTRODUCTION}

The theory of constructivism was brought by two leading theorist Jean Peaget (1930) and Lev Vygotsky (1934). Trivial (Cognitive) constructivism believes that knowledge is actively constructed by the learner, not passively received from the environment. Learners are innovating new understanding influenced by their experience and prior knowledge. It is derived from the assimilation-accommodation and schema models of Piaget. Social constructivism. was the theory of Vygotsky in the late 1970's. Vygotsky's point of view was that acquisition and participation were synergistic strategies in learning situations. Aspects of participation involved teaching in contexts that could be meaningful to students based on their personal and social history, negotiating, class discussions, small group collaborative learning with projects and tasks, and valuing meaningful activity over correct answers. Social constructivism emphasizes that learning takes place through interactions with other students, teachers, and the world-at-large (Aljohani, 2017: 97-107)

Cahyono \& Widiati (2009) state that in Indonesia, there are several aspects need to be considered in teaching listening. The first, EFL listening is integrated language skill. It is done integrated with other skills; speaking, reading and writing. The second, listening activities are designed to improve students listening ability. This concerns the development of various teaching and listening techniques that have been applied in English classrooms or in English language laboratories. The third is language teaching media used to teach EFL listening. The types of media may vary from the use of tape or CD players in the classroom to the use of multi-media language laboratory. 
Nunan (2002) says that Listening as one of the language skill is essential not only as a receptive skill but also to the development of spoken language proficiency. Richard (2008) sees listening in two different perspectives; listening as comprehension and listening as acquisition. Listening for comprehension is the traditional nature of listening. This views listening as the process of understanding the meaning in a spoken discourse, while listening for acquisition focus on listening as the process of deriving other skill such as speaking.

Richards (2008: 1-20) in Rexhaj (2016: 5-22) states that the attitude towards listening skill in the scope of ELT, has shifted in the last five decades. Initially, listening was seen only as a process of identifying and distinguishing contractions, words, and linking words in sentences. Recent views are based on cognitive psychology by introducing the concept of bottom-up and top-down approaches and turning the focus towards the role of prior knowledge schematic structuring during the process of understanding and interpreting the listening text.

\section{Cognitive Constructivism}

Constructivism is considered as an innovative approach which influences the method of teaching. It creates strategy which enables the students to gain knowledge themselves through correlating their previous knowledge and personal perspective. It is student-centered learning which the teacher plays as the facilitator not the only resource in the teaching and learning process.

The main conception of constructivist theories is that students create their own knowledge through experience. Constructivism has its foundations in the cognitive theories of Piaget and Vygotsky and embraces several aspects of both of those theories. From Piaget we learn active learning, schemes, assimilation and accommodation, etc. From Vygotsky we learn social constructivism, group work, apprenticeship, etc. Constructivism embraces a "top-down" rather than a "bottomup" instructional methodology. In conclusion, rather than teach all of the details that lead to a main idea, students need to discover the main idea and then derive the detail (Aljohani, 2017: 97-107).

Piaget's (McLeod, 2018) theory of cognitive development explains how a child constructs a mental model of the world. He disagreed with the idea that intelligence was a fixed trait, and regarded cognitive development as a process which occurs due to biological maturation and interaction with the environment. According to Piaget, children are born with a very basic mental structure (genetically inherited and evolved) on which all subsequent learning and knowledge are based. To Piaget, cognitive development was a progressive reorganization of mental processes as a result of biological maturation and environmental experience. Children construct an understanding of the world around them, then experience discrepancies between what they already know and what they discover in their environment.

Piaget and Inhelder (1969) believed that the fundamental basis of learning was discovery. Hoover in Mvidudu\&Thieal-Burgess (2012) introduces two important concepts deal with the simple idea of constructed new knowledge. The first is that learners construct new understandings using prior knowledge. Students possess knowledge, gained from previous experiences. That prior knowledge 
influences what new or modified knowledge they will construct from the new learning experiences. The second notion is that learning is active rather than passive. Learners negotiate their understanding in light of what they encounter in the new learning situation. If what learners encounter is inconsistent with their current understanding, their understanding can change to accommodate new experience. Learners remain active throughout this process.

Constructivist learning theory offers student-centered classroom activity. According to Wang (2014), William and Burden (2000), and Liu and Luan (2012) in Guixia (2016:1-5) constructivist learning theory stimulates learners' creativity. Constructivist believes that each of us constructs the meaning or constructs the world or experience from our birth under the influence of our environment. Constructionist develops from psychology in behavior and cognitive psychology. Constructive teaching advocates student-centered learning and students' autonomy under teachers' direction.

The constructivist teaching process omits the misconception that teachers is the only source in learning. Tovolovcan\&Matijevic (2017: 47-67) claims that in a new didactic learning scenario students became active subjects who research, discover, solve problems, collaborate, and think critically about everything they do and learn. In other words, it is not possible to transfer or teach knowledge to someone, but it is the individual who constructs their own knowledge based on their prior knowledge, emotional state, and own (critical) thinking, in interaction and communication.

Constructivism has important implications for teaching (Hoover, 1996);

1. Teaching cannot be viewed as the transmission of knowledge from the enlightened to the unenlightened; constructivist teachers act as "guides" who provide students with opportunities to test the adequacy of their current understandings.

2. Learning is based on prior knowledge. Teachers must take note of that knowledge and provide learning environments that exploit inconsistencies between learners' current understandings and the new experiences before them.

3. Students must apply their current understandings in new situations in order to build new knowledge, then teachers must engage students in learning, bringing students' current understandings to the forefront (Hoover, 1996).

Teachers should design learning experiences base on issues that are connected to the students' need. Teachers should be able to recognize those that are important to the students, rather than the teachers' need and the educational system suggests. Teachers can also encourage group interaction which provide the students opportunity to share their prior knowledge and experience, and build up their own understanding by comparing their works.

\section{Cognitive Constructivism and Language Teaching}

Cognitive Constructivism is based on beliefs, previous knowledge, values and self- concept and deals with how an individual constructs his understanding of the world around him. This type of constructivism is found in Piaget's work. He advocates that knowledge is constructed by mapping external reality. He was not interested in knowing only the right answer to a question rather he was more 
inclined to find out how did students arrive at a particular answer or how information is interpreted and processed by the learner. He concluded that children "s plays were an important part in their intellectual development. Theory of cognitive Constructivism was pioneered by Jean Piaget, mastermind of this theory of learning. This theory is also known as "Genetic Epistemology". This theory argues that people produce knowledge and form meaning based upon their experiences. Key components of this theory are: (Sharma \&Poonam, 2016: 788792)

\section{Schemas}

Assimilation

Accommodation

Equilibrium

Fig 2: Component of Theory of Cognitive Constructivism (Sharma \&Poonam, 2016: 788-792)

Schemas According to Piaget individual has his own previous knowledge and pattern of behavior when he deals with objects, individuals and situations in life. These are called schemas. For example, a child may have a schema about a type of animal, such as a dog. If the child's sole experience has been with small dogs, a child might believe that all dogs are small, furry, and have four legs. Suppose then that the child encounters an enormous dog. The child will take in this new information, modifying the previously existing schema to include these new observations. (Sharma \&Poonam, 2016: 788-792)

Assimilation It means to adjust new information in the existing schemas in the mind. This concept of Piaget comes into operation when the child uses his schema already present in his mind over a new problem, subject or situation. (Sharma \&Poonam, 2016: 788-792)

Accommodation It means to change in the existing schemas to fit in new ideas. This concept of Piaget comes into operation when the old schema does not work and the child has to adjust the new with the old. (Sharma \&Poonam, 2016: 788792)

Equilibration Piaget believed that all children try to strike a balance between assimilation and accommodation which is achieved through a mechanism. Piaget called this process equilibration. As children progress through the stages of cognitive development, it is important to maintain a balance between applying previous knowledge (assimilation) and changing behavior to account for new knowledge (accommodation). Equilibration helps explain how children can move from one stage of thought into the next. (Sharma \&Poonam, 2016: 788-792)

The foundation assumption of a constructivist approach is that learning is about constructing knowledge, not receiving it. It is understanding and applying, not repeating. Learning is an active process, not passive. The primary message of constructivism is that active learning enables the students to construct their own knowledge and make their own meaning of what is being thought (Aljohani, 2017) 


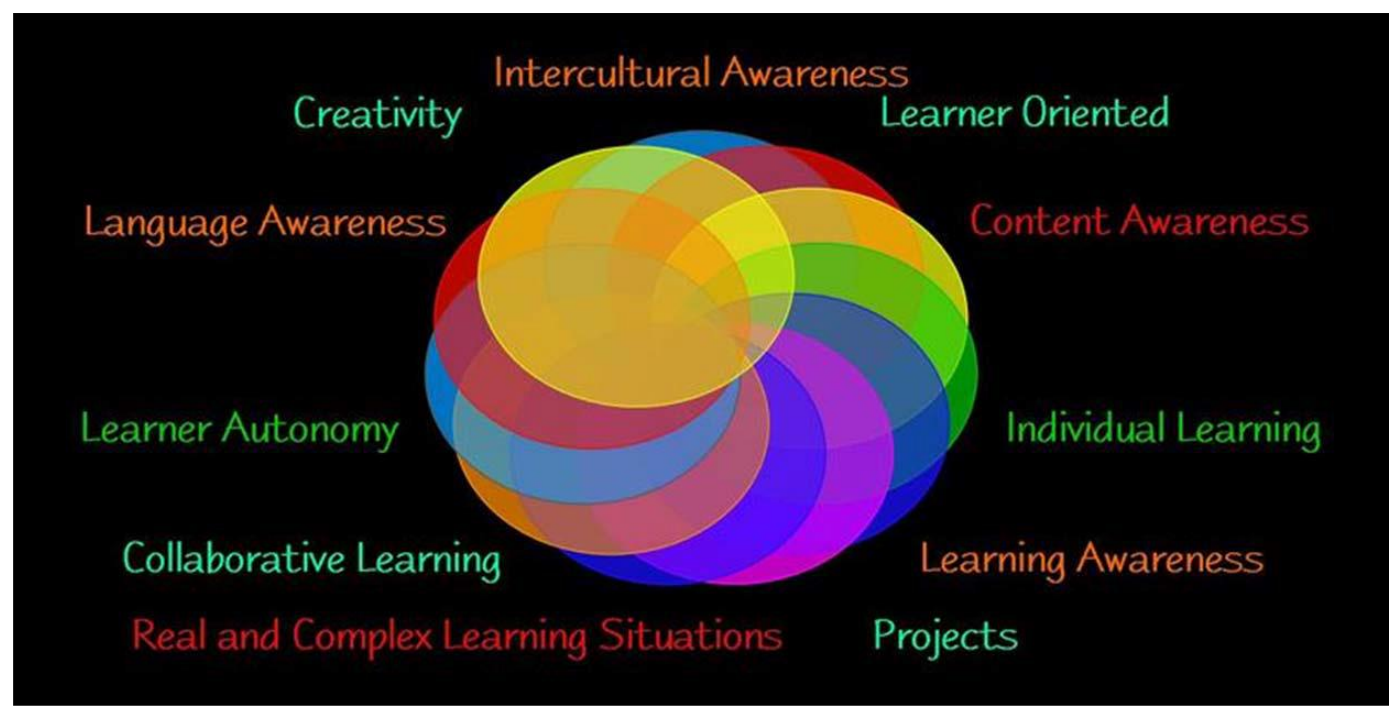

Figure 3. Principles of constructivist foreign language teaching.

\section{Principles of "Constructivist" FLT}

1. It is based on action-orientedness and cooperative learning, creative forms of classroom work, learning by projects, and, LBT - learning by teaching are essential in the constructivism classroom

2. More concentration on the Learner-centeredness which means more individualization of learning, and autonomy of learner

3. Process-related awareness is essential in the constructivist classroom and learning awareness, language awareness, intercultural awareness

4. Holistic language experience is the soul of this theory in the language classes, which depends on content-orientedness, authentic and complex learning environment. (Aljohani, 2017)

One of the most important principles in constructivist approach to language teaching is action orientedness. Cooperative learning (such as pair work, group work or any other social forms of learning), creative and active participation in classroom activities, learning by preparing various projects as well as learning by teaching (when the student is asked to take over teacher's role) have been treated as the major tasks referring to the action oriented method. The second substantial principle in constructivism FLT is individualization of learning which is centered on the learner.

Another principle of constructivism refers to holistic language experience which refers to content-oriented FLT and usually takes place in bilingual classes or project instruction. Gul (2016) reviewed several studies and show that constructivist ways of teaching English is better when compared to the traditional approach. For instance, he mentioned that Al Muhaimeed (2013) found that using a constructivist technique helped students in schools in Saudi Arabia increase reading comprehension more than that of the traditional teaching method of the English language. Nikitina (2010) also found noticeable evidence that when the students were allowed to do constructivist activities such as using visuals and 
preparing a video project with teamwork, they learned a foreign language better. She indicated that the students liked the activity and considered it as beneficial.

\section{Constructivist Activities for Language Teaching}

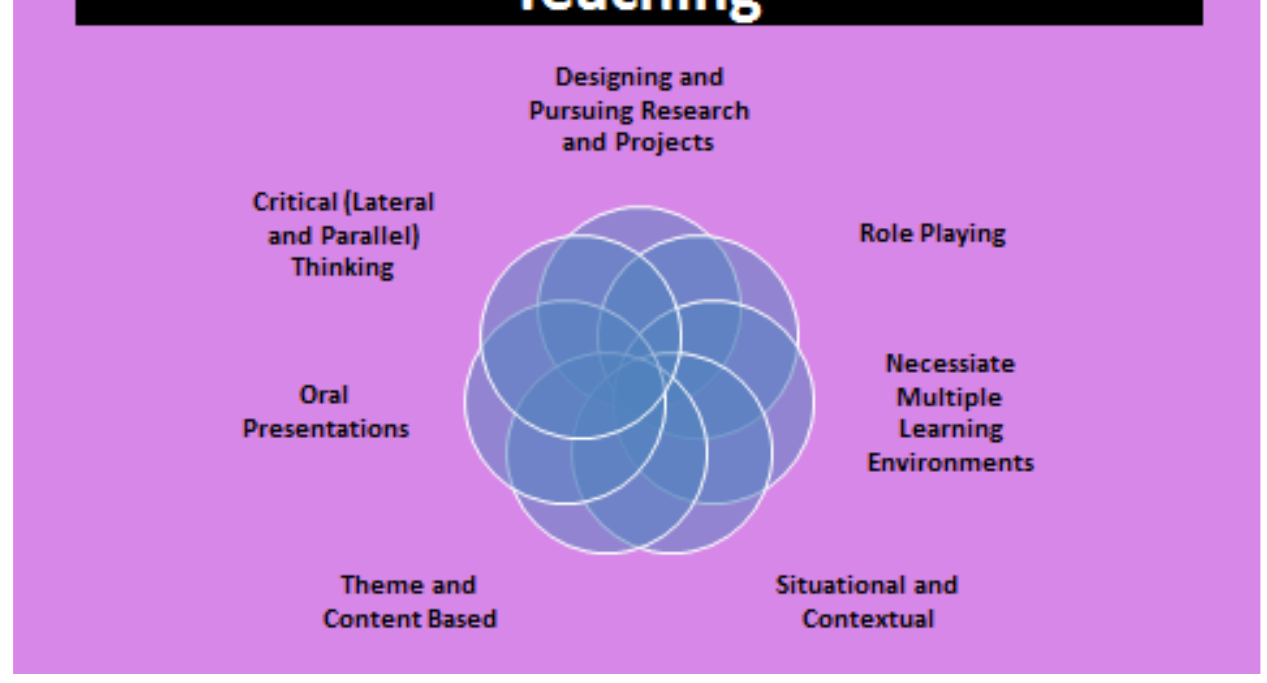

Figure 4 Constructivist activities for language teaching.

Students can construct additional knowledge by writing: poems, short plays, screenplays, legal briefs, song lyrics, journals, diaries, memoirs, travelogues, interviews, letters (or e-mail) to experts, original advertisements, new endings for stories or songs, and "what if..." thought experiments. Students can construct additional knowledge by taking/ inventing/ designing/ drawing: posters, cartoons, timelines, models, charts, maps, graphs, board games, concept maps, and multimedia presentations. Students can construct additional knowledge by performing/presenting, a play, a concert, role-play, lecture (such as a well-known person from history) and collected songs about a topic from another era (Aljohani: 2017).

\section{Cognitive Constructivism in Listening Activity}

In understanding text as spoken discourse, Richards (2008: 4-7) introduces two different kind of processes. They are often referred to as bottom-up and topdown processing. Bottom-up processing refers to the use of the incoming input as the basis for understanding the message. Comprehension begins with the received data that is analyzed at the levels of organization - sounds, words, clauses, sentences, texts-until meaning is derived. Comprehension is viewed as a process of decoding. While Top-down processing, on the other hand, refers to the use of background knowledge in understanding the meaning of a message. Whereas bottom-up processing goes from language to meaning, top-down processing goes from meaning to language. The background knowledge required for top-down processing may be previous knowledge about the topic of discourse, situational or contextual knowledge, or knowledge in the form of "schemata" or "scripts"-plans about the overall structure of events and the relationships between them. 
Rexhaj (2016) did a research on constructivist approach for improving the listening language skill. Useful data on the utilization of constructivist approaches in developing listening skills in students were collected from qualitative (observations and interviews) and quantitative research (questionnaires with 229 teachers of English language). This research identifies a number of teaching and learning strategies applied to develop student listening skills in the curricular area of languages and communication in Kosovo. It also outlines challenges and difficulties witnessed during a wider qualitative and quantitative research into the application of constructivist approaches in teaching and learning of English language in Kosovo schools. The research shows that listening skills activities are probably the least represented learning activities in the observed classes; this applies also to activities observed at lower level courses (grades five and six), where one expects to witness more language input than language output activities. As a matter of fact, there are listening activities present in all classes, but these are not carefully planned, purposeful and coherent learning efforts targeted at developing student active listening skills.

By adopting the key component theory of cognitive constructivism and the Top-down and Bottom-up listening processes, it will facilitate students to improve their listening skill and their critical thinking skill. Tovolovcan\&Matijevic (2017: 47-67) claims that in a new didactic learning scenario students became active subjects who research, discover, solve problems, collaborate, and think critically about everything they do and learn. In other words, it is not possible to transfer or teach knowledge to someone, but it is the individual who constructs their own knowledge based on their prior knowledge, emotional state, and own (critical) thinking, in interaction and communication.

Table 1.Cognitive Constructivist approach for Teaching Listening Topic: how to learn English effectivefully

\begin{tabular}{|l|l|l|}
\hline $\begin{array}{l}\text { Phase/ } \\
\text { activity/approach }\end{array}$ & Bottom-up & Top-down \\
\hline Before listening & $\begin{array}{l}\text { Review on the } \\
\text { vocabulary that } \\
\text { might be used for } \\
\text { explaining 'how to } \\
\text { learn English' }\end{array}$ & $\begin{array}{l}\text { Students reveal } \\
\text { their prior } \\
\text { understanding, } \\
\text { knowledge and } \\
\text { experience about } \\
\text { learning English. } \\
\text { 'what did you do to } \\
\text { learn English well?' }\end{array}$ \\
\hline During listening & $\begin{array}{l}\text { Undertanding } \\
\text { words, using verb } \\
\text { forms, structural } \\
\text { exercises, } \\
\text { Meaning of the } \\
\text { text }\end{array}$ & $\begin{array}{l}\text { Verification of } \\
\text { assumption from } \\
\text { the first phase with } \\
\text { the new } \\
\text { information they've } \\
\text { just learnt from the } \\
\text { text }\end{array}$ \\
\hline After listening & Summarising, & Constructing a new \\
\hline
\end{tabular}




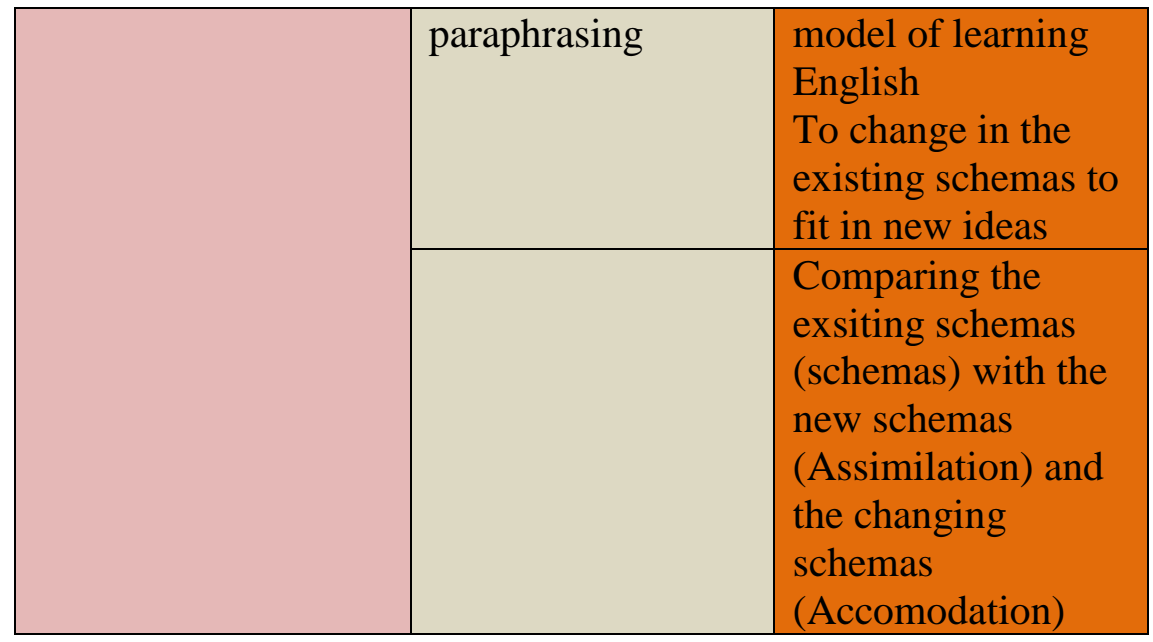

\section{CONCLUSION}

There are two listening approaches: bottom-up and top-down approach. The bottom-up approach is an identification and decoding approach. Students focus on spoken text and, based on their vocabulary and grammar knowledge, process and analyze one after the other, sounds, words, phrases, sentences and the entire text during the decoding process, to grasp the meaning of the text. On the other hand "the top-down approach refers to the context and the use of prior knowledge to grasp the meaning of a message. While the bottom-up approach moves from language to meaning, the top-down approach starts from meaning to achieve language. The knowledge sought could be information, situational or contextual knowledge and schemes, different paradigms and general relations students have about the topic"(Richard, 2008).

I attemp to bring ideas of teaching technique on listening by adopting constructivist approach and bottom up and top-down listening approach. To illustrate the approaches discussed, I make an adjustment by combining the stages of listening activities in class by Field and the Richards concept of top-down and bottom-up approaches through the elaboration of the topic of English Learning.

\section{REFERENCES}

Aljohani, Muna. (2017) Principles of "Constructivism" in Foreign Language Teaching. Journal of Literature and Art Studies. 7, (1), 97-107

Guixia, Song (2016) Constructivism in Audiovisual and Speaking Teaching of University. Higher Education of Social Science, 10 (2), 1-5

Gul, A. (2016). Constructivism as a new notion in English language education in Turkey (A dissertation submitted to the Kent State University College of Education, Health, and Human Services in partial fulfillment of the requirements for the degree of Doctor of Philosophy, Kent University)

Hoover, W. A. (1996). The practice implications of constructivism. SEDLetter 9, (3). 
Kim, Jong Suk. (2005) The Effects of a Constructivist Teaching Approach on Student Academic Achievement, Self-concept, and Learning Strategies. Asia Pacific Education Review. 6,(1), 7-19.

McLeod, Saul. (2018) JeanPeaget's Theory of Cognitive Development. https://www.simplypsychology.org/piaget.html (accessed at 10 Descember 2018)

Mvududu, Nyaradzo\& Burgess, Jennifer Thiel (2012) Constructivism in Practice: The Case for English Language Learners. International Journal of Education 4, (3), 108-119

Olesegum, Steve. (2015). Constructivism Learning Theory: A Paradigm for Teaching and Learning. IOSR Journal of Research \& Method in Education. 5 (6), 66-70

Phillips, D. C. (2000). Constructivism in education: Opinions and second opinions on controversial issues. Chicago: Ninety-Ninth Yearbook of the National Society for the study of Education, Part I.

Piaget, J., \&Inhelder, B. (1969). The psychology of the child. New York: Basic Books.

Rexhaj, Xhavit (2016) Constructivist Approach and Srategies for Improving the Listening language Skill. Thesis. https://dspace.aab-edu.net/.../01-2016EN-03-Xhavit-Rexhaj accessed at 20 Maret 2018

Richards, Jack C. (2008). Teaching Listening and Speaking: From Theory to Practice. New York: Cambridge University Press

Sharma, Hemant \& Poonam (2016) Constructivist Approach for Teaching English: Making Sense of Paradigm Shift from the Traditional Approach. International Journal of Science and Research, 5, 788-792

Topolovčan, Tomislav and Matijević, Milan. (2017). Critical Thinking as a Dimension of Constructivist Learning: Some of the Characteristics of Students of Lower Secondary Education in Croatia. C.E.P.S. Journal. 7 (3), 47-67

Vygotsky, L. (1978). Interaction between learning and development.Readings on the development of children, 23(3), 34-41. 